\title{
Metformin Use and the Outcome of Metastatic Renal Cell Carcinoma Treated with Sunitinib or Pazopanib
}

\author{
Ondřej Fiala (iD ${ }^{1,2}$ \\ Pavel Ostašov (iD ${ }^{3}$ \\ Aneta Rozsypalová 4 \\ Milan Hora ${ }^{5}$ \\ Ondřej Šorejs ${ }^{1,2}$ \\ Jan Šustr iD I \\ Barbora Bendová ${ }^{5}$ \\ Ivan Trávníček ${ }^{5}$ \\ Jan Filipovský ${ }^{6}$ \\ Jindřich Fínek' \\ Tomáš Büchler (iD) ${ }^{4}$ \\ 'Department of Oncology and \\ Radiotherapy, Faculty of Medicine and \\ University Hospital in Pilsen, Charles \\ University, Pilsen, Czech Republic; \\ ${ }^{2}$ Laboratory of Cancer Treatment and \\ Tissue Regeneration, Biomedical Center, \\ Faculty of Medicine in Pilsen, Charles \\ University, Pilsen, Czech, Czech Republic; \\ ${ }^{3}$ Laboratory of Tumor Biology and \\ Immunotherapy, Biomedical Center, \\ Faculty of Medicine in Pilsen, Charles \\ University, Pilsen, Czech, Czech Republic; \\ ${ }^{4}$ Department of Oncology, First Faculty \\ of Medicine, Charles University and \\ Thomayer Hospital, Prague, Czech \\ Republic; ${ }^{5}$ Department of Urology, \\ Faculty of Medicine and University \\ Hospital in Pilsen, Charles University, \\ Pilsen, Czech Republic; ${ }^{6}$ 2nd Department \\ of Internal Medicine, Faculty of Medicine \\ and University Hospital in Pilsen, Charles \\ University, Pilsen, Czech Republic
}

Correspondence: Ondřej Fiala Department of Oncology and Radiotherapy, Faculty of Medicine and University Hospital Pilsen, Charles University Prague, Alej Svobody 80 ,

Pilsen, CZ-304 60, Czech Republic

Tel +420728655488

Email fialao@fnplzen.cz
Background: The anticancer properties of metformin have been suggested in numerous experimental studies and several retrospective clinical studies show that its use is associated with improved outcome of patients with cancer. However, limited data are available for patients with metastatic renal cell carcinoma ( $\mathrm{mRCC}$ ) treated with targeted therapy. The aim of this retrospective study was to assess the impact of the metformin use on survival of mRCC patients treated with sunitinib or pazopanib.

Methods: Clinical data from 343 patients with mRCC treated with sunitinib or pazopanib in the first line were analyzed. Progression-free survival (PFS) and overall survival (OS) were compared according to the use of metformin.

Results: The median PFS and OS for patients using metformin was $31.1(95 \% \mathrm{CI}$ 20.6-35.1) and 51.6 (95\% CI 44.7-NR) months compared to 9.3 (95\% CI 8.0-12.0) and 22.4 (95\% CI 19.4-26.8) months for patients not using metformin $(p<0.0001$ and $p=0.0002$, respectively). Cox multivariate analysis shows that the use of metformin remains a significant factor for PFS ( $\mathrm{HR}=0.55$ [95\% CI $0.343-0.883$ ], $p=0.013)$ and also for OS (HR=0.45 [95\% CI 0.256-0.794], $p=0.006)$.

Conclusion: The present study results suggest that the use of metformin was associated with favorable outcome of mRCC patients treated with sunitinib or pazopanib.

Keywords: renal cell carcinoma, metformin, sunitinib, pazopanib, tyrosine kinase inhibitors, outcome

\section{Background}

Renal cell carcinoma (RCC) represents a common urologic malignancy, with increasing incidence in the recent years. ${ }^{1,2}$ Antiangiogenic tyrosine kinase inhibitors, such as sunitinib and pazopanib, although no longer treatment of first choice, are still widely used as the first-line treatment of patients with metastatic RCC (mRCC) with favorable or intermediate risk according to the Memorial Sloan-Kettering Cancer Center (MSKCC) prognostic model. ${ }^{3,4}$ Metformin (dimethylbiguanide) is a commonly prescribed oral antidiabetic drug (OAD), widely used for the management of type 2 diabetes mellitus. ${ }^{5}$ It improves glycemic control and reduces insulin resistance. ${ }^{6}$ There has been a growing body of evidence indicating that metformin has several anticancer properties shown in a number of experimental studies. ${ }^{7,8}$ The anticancer activity of metformin is related to both direct effects on cancer cells based on inhibition of various cancer-related signaling pathways and also indirect effects on the host 
based on lowering blood glucose and insulin as well as anti-inflammatory effect. ${ }^{7,8}$ Although experimental studies have suggested anticancer activity of metformin, its impact on outcomes of cancer patients is still poorly understood. Several retrospective observational studies show that the use of metformin was associated with favorable prognosis of patients with various cancer types; however, there are limited data on its role in patients with $\mathrm{mRCC}$ treated with antiangiogenic targeted agents. $^{9-13}$

The aim of this retrospective study was to evaluate the association between the use of metformin and outcome of mRCC patients treated with sunitinib or pazopanib in the first line.

\section{Patients and Methods Study Design}

Clinical data were analyzed retrospectively. Progressionfree survival (PFS) and overall survival (OS) according to the use of metformin were assessed. The clinical data were obtained from the national Renal Cell Carcinoma Information System (RENIS) registry, which provides retrospective anonymized data on patient baseline clinical characteristics as well as on previous therapies for mRCC, laboratory parameters, treatment course and outcomes, and toxicity that are updated twice a year (http:// renis.registry.cz). ${ }^{14}$ Data on comedication were extracted from the hospital information systems and merged with the registry data. The RENIS registry and the use of registry data for analysis were approved on May 15, 2013 by the Multicentre Ethics Committee of the Masaryk Memorial Cancer Institute in Brno, Czech Republic. All the patients signed informed consent with the inclusion of their data in the registry.

\section{Patients and Treatment}

In total, 343 adult patients with histologically confirmed mRCC treated with sunitinib or pazopanib in the first line of systemic targeted therapy between 2007 and 2020 at two oncology centers in the Czech Republic were included in the study. The patients were treated at Department of Oncology and Radiotherapy, Faculty of Medicine and University Hospital in Pilsen and Department of Oncology, First Faculty of Medicine and Thomayer Hospital, Charles University.

Sunitinib (Sutent, Pfizer Inc., NYC, New York, USA) was administered orally as a single agent in the standard approved schedule $(50 \mathrm{mg} / 4$ weeks on 2 weeks off or $50 \mathrm{mg} / 2$ weeks on 1 week off). Pazopanib (Votrient, Glaxo Smith Kline plc., Brentford, UK) was administered orally as a single agent in the standard approved schedule ( $800 \mathrm{mg}$ daily). The treatment was continued until disease progression, unacceptable toxicity, or patient refusal. Temporary discontinuation or dose reductions for toxicity followed clinical practice guidelines. None of the patients had received prior targeted therapy. Patients treated with cytokine immunotherapy before targeted treatment were not excluded. The status of the OAD therapy was assessed at the start of the targeted therapy and all the OADs were administered orally at individual doses under the supervision of treating diabetologist.

\section{Outcome Assessment}

The clinical status of the patients was assessed continuously during visits at pre-specified time points. Physical examination and routine laboratory tests were performed every two weeks, and computed tomography (CT) was performed every three to four months during the treatment. The objective tumor response was assessed locally by the independent radiologist using Response Evaluation Criteria in Solid Tumors (RECIST) version 1.1. ${ }^{15}$

\section{Statistical Analysis}

Descriptive statistics and standard frequency tables were used to characterize the sample data set. Metformin users vs non-users were compared according to the baseline clinical parameters using Pearson's Chi-Square test. PFS was determined from the date of treatment initiation until the date of first documented progression or death. OS was determined from the date of treatment initiation until the date of death. PFS and OS were estimated using the Kaplan-Meier method and all point estimates were accompanied by two-sided $95 \%$ confidence intervals. The statistical analysis was performed using $\mathrm{R}$ (version 4, the $\mathrm{R}$ Foundation for Statistical Computing, Vienna, Austria) and packages survival (version 3.2) and survminer (0.4.8) for survival analysis and visualization. The Log rank test was used for assessment of statistical significance of the differences in survival according to treatment. A multivariable Cox proportional hazards model was used to evaluate the effect of all potential prognostic factors on the survival indicators, namely: gender, age, 
Table I Patient Characteristics

\begin{tabular}{|c|c|c|c|}
\hline & \multicolumn{2}{|c|}{ Metformin Use } & \multirow[t]{2}{*}{ Chi-Square $p$-value } \\
\hline & No $(n=307)$ & Yes $(n=36)$ & \\
\hline Gender & & & 1.000 \\
\hline Male & $228(74.3)$ & $27(75.0)$ & \\
\hline Female & $79(25.7)$ & $9(25.0)$ & \\
\hline Age at diagnosis (years) & & & \\
\hline Median (range) & $65(37-83)$ & $64(52-83)$ & \\
\hline ECOG PS & & & 0.432 \\
\hline 0 & $92(30.0)$ & 8 (22.2) & \\
\hline I & $215(70.0)$ & $28(77.8)$ & \\
\hline BMI & & & 0.055 \\
\hline Low $(\leq 25)$ & $52(16.9)$ & $2(5.6)$ & \\
\hline High $(>25)$ & 152 (49.5) & $26(72.2)$ & \\
\hline Unknown & $103(33.6)$ & $8(22.2)$ & \\
\hline Type 2 diabetes mellitus & & & - \\
\hline Yes & $16(5.2)$ & $36(100.0)$ & \\
\hline No & 291 (94.8) & 0 & \\
\hline Histology & & & 1.000 \\
\hline Clear cell carcinoma & $287(93.5)$ & $34(94.4)$ & \\
\hline Non-clear cell carcinoma & $17(5.5)$ & $2(5.6)$ & \\
\hline Unknown & $3(1.0)$ & $0(0.0)$ & \\
\hline Primary tumor grade & & & 0.011 \\
\hline GI-2 & $165(53.7)$ & $25(69.4)$ & \\
\hline G3-4 & $|2|(39.4)$ & $5(13.9)$ & \\
\hline Unknown & $21(6.8)$ & $6(16.7)$ & \\
\hline Synchronous metastatic & & & 0.106 \\
\hline disease & & & \\
\hline Yes & $138(45.0)$ & $10(27.8)$ & \\
\hline No & $165(53.7)$ & $24(66.7)$ & \\
\hline Unknown & $4(1.3)$ & $2(5.6)$ & \\
\hline Distant metastatic sites & & & 0.901 \\
\hline Lung & $202(65.8)$ & $22(61.1)$ & \\
\hline Liver & $41(13.4)$ & $3(8.3)$ & \\
\hline Bone & $73(23.8)$ & $9(25)$ & \\
\hline Lymph nodes (non-regional) & $125(40.7)$ & I5 (4I.7) & \\
\hline Skin & $5(1.6)$ & $0(0.0)$ & \\
\hline Brain & $12(3.9)$ & I (2.8) & \\
\hline Peritoneum & $15(4.9)$ & $3(8.3)$ & \\
\hline Other & $80(26.1)$ & $12(33.3)$ & \\
\hline MSKCC risk group & & & 0.423 \\
\hline Favorable-risk group & $119(38.8)$ & 17 (47.2) & \\
\hline Intermediate-risk group & $188(6 \mid .2)$ & $19(52.8)$ & \\
\hline Previous nephrectomy & & & 0.542 \\
\hline Yes & $256(83.4)$ & $28(77.8)$ & \\
\hline No & 51 (16.6) & $8(22.2)$ & \\
\hline
\end{tabular}

(Continued) 
Table I (Continued).

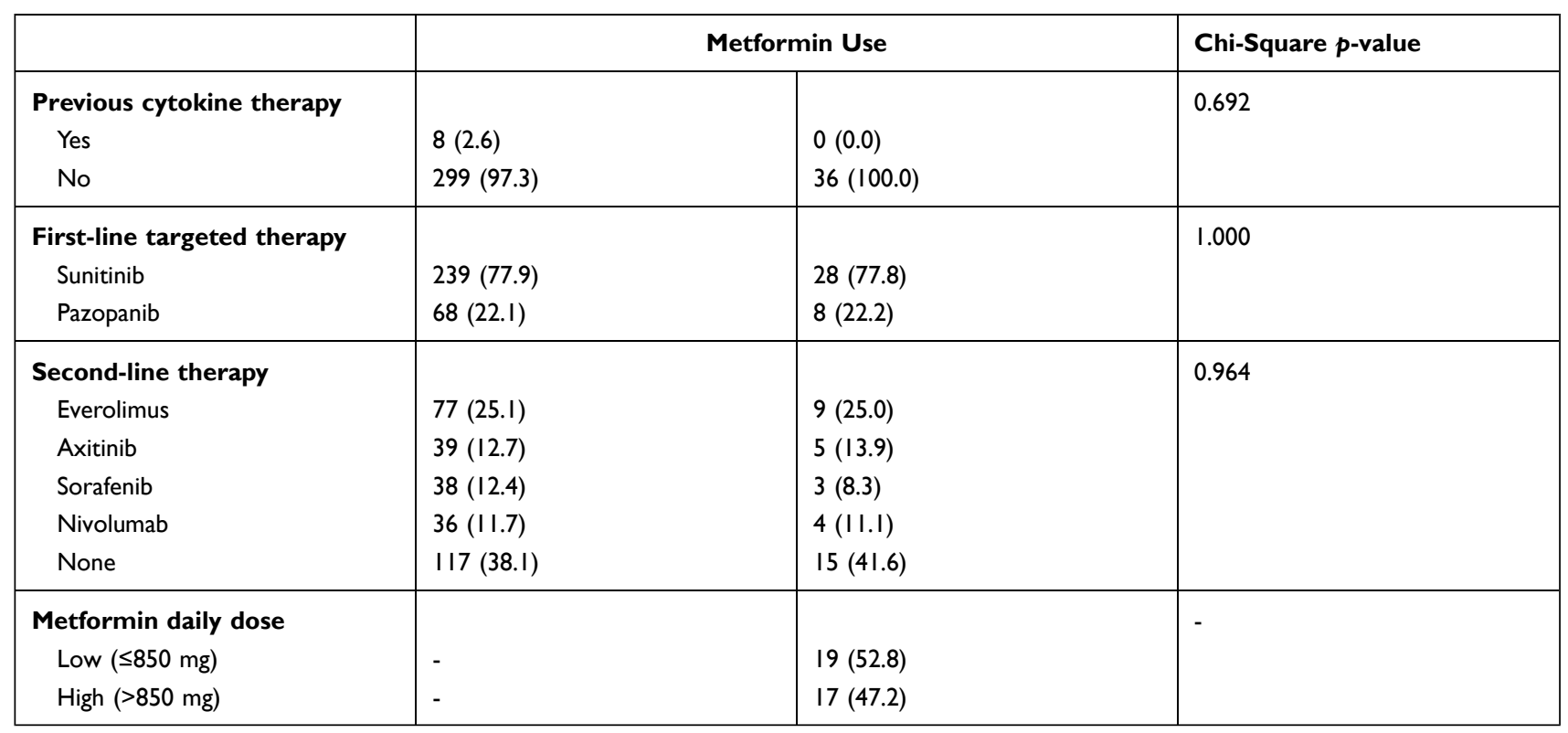

Note: Bold indicates $p<0.05$.

Abbreviations: n, number of included patients; ECOG PS, Eastern Cooperative Oncology Group performance status; MSKCC, Memorial Sloan-Kettering Cancer Center (MSKCC) risk; BMI, body mass index; GI, well differentiated; G2, moderately differentiated; G3/G4, poorly differentiated/undifferentiated.

ECOG PS, BMI, histology, grade, synchronous metastatic spread, MSKCC risk group, previous nephrectomy, first-line targeted agent and metformin use. The level of statistical significance was set at $\alpha=0.05$ and all reported $p$-values are two-tailed.

\section{Results}

\section{Patient Characteristics}

The study included $343 \mathrm{mRCC}$ patients. At the time of data analysis 291 (84.8\%) patients progressed and 274 (79.9\%) patients died. The median follow-up time was
19.9 months. At the time of targeted therapy initiation $36(10.5 \%)$ patients were using metformin and $7(2.0 \%)$ were using other OADs, predominantly sulfonylureas. Baseline characteristics of the patient group are described in Table 1.

There were important differences between patients using metformin and others in several disease-related parameters, possibly reflecting the impact of metformin on the biology of RCC. The cohort of metformin nonusers included more patients with G3-4 tumors (39.4\% vs $13.9 \%, p=0.004)$.

Table 2 Progression-Free and Overall Survival According to the Use of Metformin

\begin{tabular}{|c|c|c|c|}
\hline & \multicolumn{2}{|c|}{ Metformin Use } & \multirow[t]{2}{*}{$p$-value } \\
\hline & No & Yes & \\
\hline Median PFS (CI 95\%) & 9.3I Months (8.03-12.00) & 31.13 Months (20.62-35.10) & $<0.0001$ \\
\hline 3-months PFS (Cl 95\%) & $0.879(0.843-0.916)$ & $0.972(0.920-1.000)$ & \\
\hline 6-months PFS (Cl 95\%) & $0.613(0.56 \mathrm{I}-0.670)$ & $0.916(0.831-1.000)$ & \\
\hline I2-months PFS (CI 95\%) & $0.443(0.390-0.502)$ & $0.833(0.720-0.964)$ & \\
\hline I8-months PFS (CI 95\%) & $0.274(0.228-0.329)$ & $0.750(0.62 I-0.906)$ & \\
\hline Median OS (Cl 95\%) & 22.40 Months $(19.40-26.80)$ & 5 I.60 Months (44.70-NA) & 0.0002 \\
\hline I2-months OS (CI 95\%) & $0.710(0.66 I-0.763)$ & $0.915(0.828-1.000)$ & \\
\hline 24-months OS (Cl 95\%) & $0.473(0.420-0.534)$ & $0.858(0.750-0.98 I)$ & \\
\hline 36-months OS (Cl 95\%) & $0.350(0.299-0.409)$ & $0.769(0.64 I-0.923)$ & \\
\hline
\end{tabular}

Note: Bold indicates $p<0.05$.

Abbreviations: PFS, progression-free survival; OS, overall survival. 


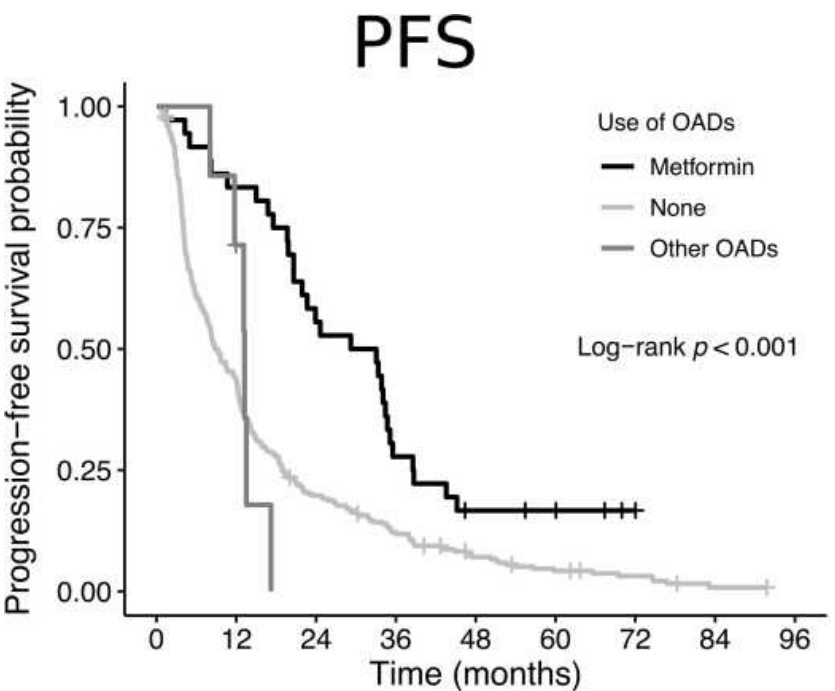

No. at risk

$\begin{array}{ccccccccc}36 & 30 & 20 & 10 & 5 & 4 & 1 & 0 & 0 \\ -300 & 130 & 58 & 35 & 18 & 10 & 6 & 1 & 0 \\ 7 & 4 & 0 & 0 & 0 & 0 & 0 & 0 & 0\end{array}$

OS

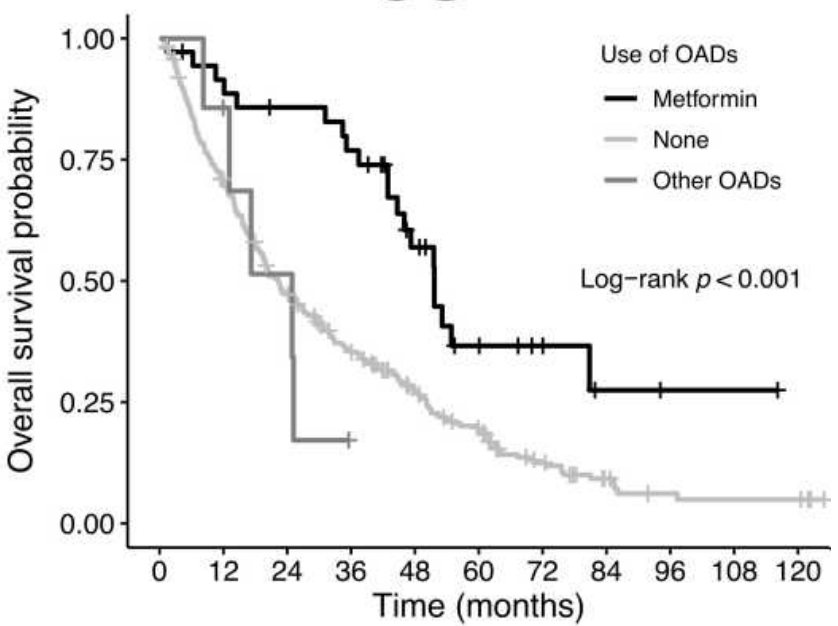

No. at risk

$\begin{array}{ccccccccccc}36 & 32 & 29 & 26 & 16 & 8 & 5 & 2 & 1 & 1 & 0 \\ 300 & 207 & 135 & 96 & 65 & 42 & 21 & 10 & 5 & 4 & 4 \\ 7 & 5 & 3 & 0 & 0 & 0 & 0 & 0 & 0 & 0 & 0\end{array}$

Figure I Kaplan-Meier estimates of progression-free survival (PFS) and overall survival (OS) according to the use of metformin and other OADs.

\section{Outcome of Patients According to the Use of Metformin}

The median PFS and OS for patients using metformin was 31.1 (95\% CI 20.6-35.1) and 51.6 (95\% CI 44.7-not reached) months compared to 9.3 (95\% CI 8.0-12.0) and
22.4 (95\% CI 19.4-26.8) months for patients not using metformin $(p<0.0001$ and $p=0.0002$, respectively) (Table 2, Figure 1).

The median PFS and OS for patients using higher (>850 mg) daily dose of metformin was 34.2 (95\% CI

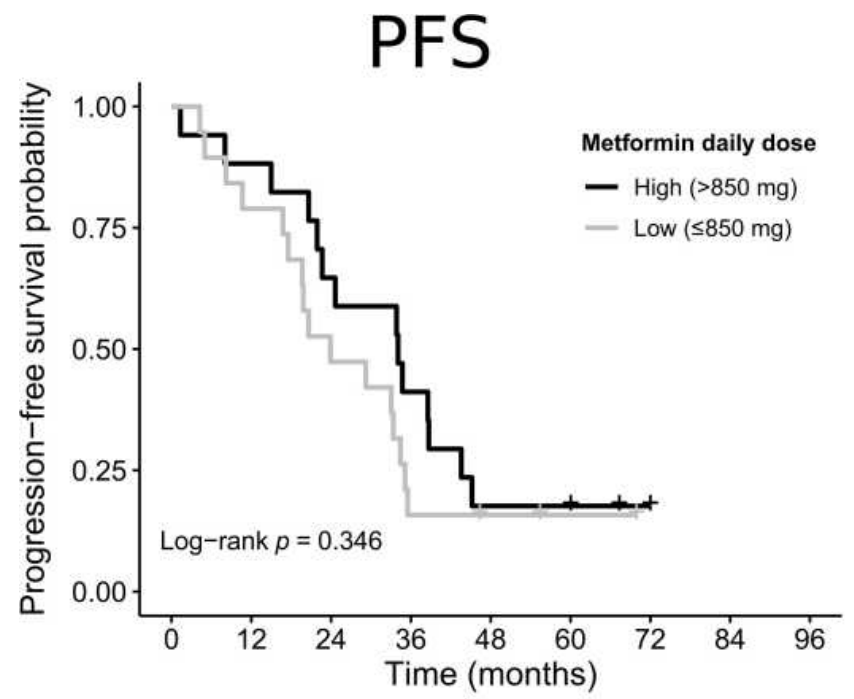

No. at risk

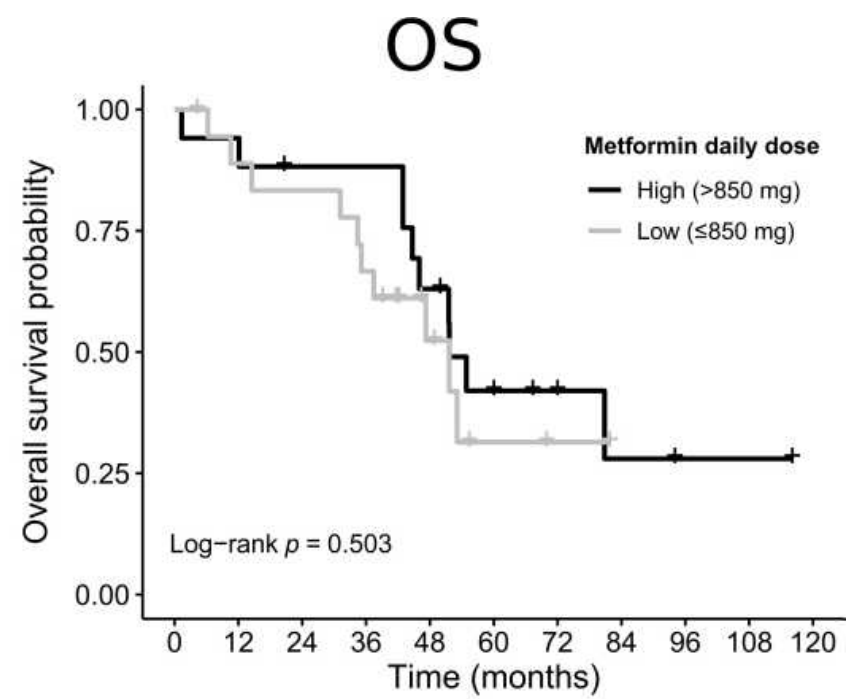

No. at risk

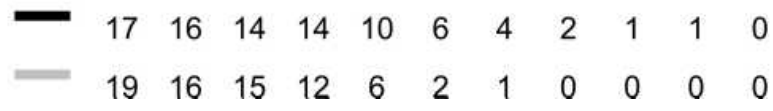

Figure 2 Kaplan-Meier estimates of progression-free survival (PFS) and overall survival (OS) according to the dose of metformin. 
Table 3 Multivariate Cox-Proportional Hazards Model for Progression-Free and Overall Survival

\begin{tabular}{|c|c|c|c|c|c|}
\hline \multirow[t]{2}{*}{ Characteristic } & \multirow[t]{2}{*}{ Category } & \multicolumn{2}{|c|}{ Progression-Free Survival (PFS) } & \multicolumn{2}{|c|}{ Overall Survival (OS) } \\
\hline & & HR (95\% Cl) & $p$-value & HR (95\% Cl) & $p$-value \\
\hline \multicolumn{6}{|l|}{ Gender } \\
\hline & Female & 1 & & 1 & \\
\hline & Male & $0.793(0.574-1.096)$ & 0.160 & $0.830(0.579-1.189)$ & 0.309 \\
\hline \multicolumn{6}{|l|}{ Age } \\
\hline & $<65$ years & I & & I & \\
\hline & $\geq 65$ years & $0.877(0.657-1.170)$ & 0.371 & $0.89 \mid(0.649-\mid .224)$ & 0.477 \\
\hline \multicolumn{6}{|l|}{ ECOG PS } \\
\hline & 1 & I & & I & \\
\hline & 0 & $0.665(0.487-0.909)$ & 0.010 & $0.665(0.479-0.924)$ & 0.015 \\
\hline \multicolumn{6}{|l|}{ BMI } \\
\hline & Low $(\leq 25)$ & I & & I & \\
\hline & High $(>25)$ & $1.090(0.768-1.547)$ & 0.630 & $1.349(0.914-1.990)$ & 0.132 \\
\hline \multicolumn{6}{|l|}{ Histology } \\
\hline & Clear cell carcinoma & I & & I & \\
\hline & Other & $2.286(1.184-4.414)$ & 0.014 & $1.970(0.974-3.984)$ & 0.059 \\
\hline \multicolumn{6}{|l|}{ Grade } \\
\hline & GI-G2 & I & & I & \\
\hline & G3-G4 & $1.417(1.043-1.926)$ & 0.026 & $\mathrm{I} .889(\mathrm{I} .35 \mathrm{I}-2.640)$ & $<0.001$ \\
\hline \multicolumn{6}{|c|}{ Synchronous metastases } \\
\hline & No & I & & I & \\
\hline & Yes & $0.943(0.660-1.348)$ & 0.748 & $0.935(0.635-1.376)$ & 0.732 \\
\hline \multicolumn{6}{|c|}{ MSKCC risk group } \\
\hline & Favorable-risk group & I & & 1 & \\
\hline & Intermediate-risk group & $0.987(0.724-1.345)$ & 0.932 & $1.310(0.944-1.820)$ & 0.106 \\
\hline \multicolumn{6}{|c|}{ Previous nephrectomy } \\
\hline & No & 1 & & 1 & \\
\hline & Yes & $0.699(0.439-1.115)$ & 0.133 & $0.557(0.336-0.921)$ & 0.023 \\
\hline \multicolumn{6}{|c|}{ First-line targeted therapy } \\
\hline & Sunitinib & I & & 1 & \\
\hline & Pazopanib & $1.028(0.700-1.509)$ & 0.889 & $1.094(0.719-1.666)$ & 0.674 \\
\hline \multicolumn{6}{|l|}{ Metformin use } \\
\hline & No & I & & 1 & \\
\hline & Yes & $0.550(0.343-0.883)$ & 0.013 & $0.450(0.256-0.794)$ & 0.006 \\
\hline
\end{tabular}

Note: Bold indicates $p<0.05$.

Abbreviations: $n$, number of included patients; ECOG PS, Eastern Cooperative Oncology Group performance status; MSKCC, Memorial Sloan-Kettering Cancer Center (MSKCC) risk; BMI, body mass index; GI, well differentiated; G2, moderately differentiated; G4, poorly differentiated/undifferentiated. 
22.0-38.8) months and 51.7 (95\% CI 43.0-63.2) months compared to 24.0 (95\% CI 16.8-34.5) and 41.8 (95\% CI $31.2-49.0$ ) months for patients using lower $(\leq 850 \mathrm{mg}$ ) daily dose of metformin. Despite the numeric advantage of higher-dose metformin, the difference did not reach statistical significance in the present cohort $(p=0.346$ and $p=0.503$, respectively) (Figure 2).

In the Cox multivariate analysis, the use of metformin remains a significant factor predicting both $\mathrm{PFS}(\mathrm{HR}=0.55$ [95\% CI 0.343-0.883], $p=0.013)$ and OS $(\mathrm{HR}=0.45[95 \%$ CI 0.256-0.794], $p=0.006$ ) (Table 3). Other independent favorable prognostic factors for PFS identified in the multivariate analysis included performance status of 0 , and lower tumor grade. Favorable prognostic factors for OS included performance status of 0 , lower tumor grade, and previous nephrectomy. Age or body mass index (BMI) was not significantly associated with PFS or OS in the present cohort.

\section{Discussion}

The results of our study suggest that the use of metformin is associated with longer PFS and OS in mRCC patients treated with sunitinib or pazopanib in the first line. The impact of metformin use was confirmed in the multivariate Cox proportional hazards model showing it was an independent factor for both PFS and OS.

However, the introduction of novel systemic therapies has been leading to improvements in patient survival, the prognosis of $\mathrm{mRCC}$ has been still serious. Thus, new effective agents or innovative strategies that could further improve the efficacy of current systemic treatment are needed. Metformin represents the most commonly prescribed agent used for the management of type 2 diabetes mellitus. Metformin decreases glycaemia by inhibiting of gluconeogenesis and glycogenolysis in the liver. Moreover, it decreases intestinal glucose absorption and stimulates glucose utilization by the muscle, thus lowering insulin resistance, a principal mechanism of type 2 diabetes mellitus. ${ }^{6}$ The molecular mechanism of action of metformin is based on the activation of adenosine monophosphate-activated protein kinase (AMPK), which is a serine-threonine kinase involved in regulation of energy metabolism at the cellular level. The AMPK regulatory pathway plays a key role in the metabolism of glucose and fatty acids, through downregulation of gluconeogenesis and synthesis of fatty acids in the liver, and upregulation of glucose uptake and fatty acid oxidation by peripheral tissues. ${ }^{16}$ Aside from the antidiabetic effects, metformin has been widely studied also for its potential anticancer activity. The putative anticancer effects can be divided into the indirect and direct effects according to two general mechanisms. The indirect anticancer effects are related to antidiabetic properties including the lowering of blood glucose and insulin. This in turn inhibits insulin/insulinlike growth factor (IGF) mediated signaling pathways that play important role in cancer, namely the PI3K/AKT/ mTOR, RAS/RAF/MEK/ERK and GSK3B/Beta-catenin pathways. ${ }^{17}$ The direct anticancer effects are mainly related to the metformin-mediated activation of AMPK leading to inhibition of the mTOR, nuclear factor kappa $\mathrm{B}(\mathrm{NF}-\kappa \mathrm{B})$ and cMyc pathways and activation of p53 and DICER pathways in cancer cells. ${ }^{18}$ Besides the AMPKmediated effects, several other direct anticancer effects of metformin have been proposed, including activation of p53/REDD1 axis, inhibition of Rag GTPases and inhibition of STAT-3 nuclear translocation. ${ }^{7}$ The anticancer activity of metformin targeting various biological processes in cancer cells has been previously demonstrated in numerous experimental studies. Blockade of the cell cycle, inducing apoptosis and also improving the tumor microenvironment, is among the most important of these anticancer properties. ${ }^{8}$ Epidemiologic studies showed that metformin use was associated with reduced risk of both cancer incidence and mortality among diabetic patients. ${ }^{19-21}$ In addition, some observational studies and meta-analyses show that the use of metformin in cancer patients was associated with improved response to systemic therapy or radiotherapy, higher survival rates and better prognosis, however, the results are not consistent. $^{22-25}$ Regarding the impact of metformin use in RCC patients, limited data have been obtained from several observational studies with conflicting results. Moreover, only a few data are available for mRCC patients, particularly those treated with antiangiogenic targeted therapies. It has been demonstrated that metformin is able to affect angiogenesis mainly by downregulation of several proangiogenic and inflammatory stimuli represented by von Willebrand factor, plasminogen activator inhibitor $1, N F-\kappa B$ and tumor necrosis factor alpha and by decreasing the expression of matrix metalloproteinases. ${ }^{26-29}$ These findings suggest that metformin could work synergistically with antiangiogenic targeted therapies in cancer patients leading to enhancement of treatment efficacy. 
No impact of metformin use on recurrence or cancer-specific survival (CSS) was reported in a study conducted by Hakimi et al, which included patients undergoing surgery for localized-stage RCC. ${ }^{30}$ Similarly, no association of metformin use with CSS, OS or disease-free survival (DFS) was seen in a study by Nayan et al, which included patients with various stages of RCC. ${ }^{31}$ On the other hand, Cheng et al reported better DFS and CSS in diabetics with localized RCC, who were using metformin as compared to those using other antidiabetic medication. ${ }^{32}$ Almost identical results have been reported by Keizman et al. ${ }^{33}$ The largest study focusing on the role of metformin in mRCC in association with targeted therapy has been reported by Hamieh et al, who conducted a retrospective analysis of patients with $\mathrm{mRCC}$ enrolled in Phase II and III clinical trials. ${ }^{34}$ Their results show that among diabetics treated with sunitinib, metformin use was associated with an improvement in OS compared with users of other antidiabetic agents (29.3 vs 20.9 months, respectively; HR: 0.051; $p=0.0008$ ), but the study did not show significant difference in OS between metformin users and non-users without diabetes. ${ }^{34}$ However, strict criteria for enrolment to clinical trials may have limited the representability of the subgroup of diabetic patients.

The results of an experimental study recently reported by Pasha et al suggest dose-dependent effect of metformin on viability of clear cell RCC cell lines, but metformin concentrations applied in their study were at least more than 100-fold higher than with the peak plasma concentration of orally administered metformin in standard doses used in the clinical practice. ${ }^{35}$ In our clinical observation, there was no significant difference in patient survival according to daily dose of metformin; however, our data are limited by low number of patients in both compared groups and the fact that possible dose changes during treatment were not monitored.

Our study has several limitations including the retrospective design and limited number of patients. The duration of OAD exposure could not be assessed from the available data sources. The group of metformin nonusers included more patients with high-grade tumors, which has been previously reported as an adverse prognostic factor. ${ }^{36}$ Although this may be a consequence of small patient sample and a source of bias favoring the metformin subgroup, it could reflect the biology of metformin action on RCC cells. These parameters were included in the multivariate Cox proportional hazards model that confirmed the use of metformin as an independent factor.

Single-agent VEGF inhibitors are no longer the firstline treatment of choice for most patients with mRCC. Nevertheless, many issues identified in the present analysis and studies cited above remain relevant in the immunotherapy era where a significant number of patients are still treated with these agents in combination with checkpoint inhibitors or in later lines of therapy. Thus, the optimization of VEGF inhibition remains an important objective in mRCC.

\section{Conclusions}

The results of the present retrospective study suggest that there is a significant association between the use of metformin and favorable outcome of mRCC patients treated with sunitinib or pazopanib in the first line of targeted therapy. The efficacy and safety of combination of metformin with targeted therapy in both diabetics and nondiabetics with mRCC should be investigated in a prospective controlled clinical trial in the future.

\section{Acknowledgments}

The authors would like to thank all patients voluntarily taking part in the study.

\section{Author Contributions}

All authors made a significant contribution to the work reported, whether that is in the conception, study design, execution, acquisition of data, analysis and interpretation, or in all these areas; took part in drafting, revising or critically reviewing the article; gave final approval of the version to be published; have agreed on the journal to which the article has been submitted; and agree to be accountable for all aspects of the work.

\section{Funding}

This study was supported by the Institutional Research Fund of University Hospital Plzen, FN 00669806 and by the Charles University Research Fund (Progres Q39), by the European Regional Development Fund-Project "Application of Modern Technologies in Medicine and Industry" (No. CZ.02.1.01/0.0/0.0/17_048/0007280) and by the grant of Ministry of Health of the Czech Republic - AZV NV19-08-00250, and by the European Union's Horizon 2020 research and innovation programme under grant agreement No. 856620 . 


\section{Disclosure}

OF received honoraria from Roche, Janssen, GSK and Pfizer for consultations and lectures unrelated to this project. $\mathrm{MH}$ received honoraria for lecture, tutoring, clinical trial or travel grant from Astellas, Janssen-Cilag and Roche. OF reports personal fees from University Hospital Plzen, personal fees from Charles University, grants from European Regional Development Fund-Project, grants from Ministry of Health of the Czech Republic, grants from European Union's Horizon 2020, during the conduct of the study. JF has received honoraria from AstraZeneca, Roche and Novartis for consultations and lectures unrelated to this project. TB received lecture honoraria from Novartis, Ipsen, Pfizer, Bayer, Amgen, Servier, Bristol Myers Squibb, Astellas, Janssen, and Roche, and research support from Roche, Servier, and Novartis, all unrelated to the presented work. PO, AR, OS, JS, BB, IT and JF declare that they have no actual or potential conflicts of interest including any financial, personal or other relationships with other people or organizations that could inappropriately influence this work.

\section{References}

1. Znaor A, Lortet-Tieulent J, Laversanne M, et al. International variations and trends in renal cell carcinoma incidence and mortality. Eur Urol. 2015;67(3):519. doi:10.1016/j.eururo.2014.10.002

2. Srigley JR, Delahunt B, Eble JN, et al. The International Society of Urological Pathology (ISUP) Vancouver classification of renal neoplasia. Am J Surg Pathol. 2013;37(10):1469-1489. doi:10.1097/ PAS.0b013e318299f2d1

3. Motzer RJ, Hutson TE, Tomczak P, et al. Overall survival and updated results for sunitinib compared with interferon alfa in patients with metastatic renal cell carcinoma. J Clin Oncol. 2009;27 (22):3584-3590. doi:10.1200/JCO.2008.20.1293

4. Sternberg CN, Davis ID, Mardiak J, et al. Pazopanib in locally advanced or metastatic renal cell carcinoma: results of a randomized Phase III trial. J Clin Oncol. 2010;28(6):1061-1068. doi:10.1200/ JCO.2009.23.9764

5. Nathan DM, Buse JB, Davidson MB, et al. Medical management of hyperglycaemia in type 2 diabetes mellitus: a consensus algorithm for the initiation and adjustment of therapy: a consensus statement from the American Diabetes Association and the European Association for the Study of Diabetes. Diabetologia. 2009;52(1):17-30. doi:10.1007/ s00125-008-1157-y

6. Cusi K, DeFronzo RA. Metformin: a review of its metabolic effects. Diabetes Rev. 1998;6(2):89-131.

7. Samuel SM, Varghese E, Kubatka P, et al. Metformin: the answer to cancer in a flower? Current knowledge and future prospects of metformin as an anti-cancer agent in breast cancer. Biomolecules. 2019;9 (12):846. doi:10.3390/biom9120846

8. Chen YC, Li H, Wang J. Mechanisms of metformin inhibiting cancer invasion and migration. Am J Transl Res. 2020;12(9):4885-4901.

9. Chlebowski RT, McTiernan A, Aragaki AK, et al. Metformin and breast cancer incidence in postmenopausal diabetic women in the women's health initiative (WHI). J Clin Oncol. 2011;29(11):3-1503. doi:10.1200/jco.2011.29.15_suppl.1503
10. Bansal M, Siegel E, Govindarajan R. The effect of metformin (M) on overall survival (OS) of patients (Pts) with colorectal cancer (CRC) treated with chemotherapy (CTX). J Clin Oncol. 2011;29(15):2608. doi:10.1200/jco.2011.29.15_suppl.2608

11. Mayer MJ, Klotz LH, Venkateswaran V. The effect of metformin use during docetaxel chemotherapy on prostate cancer-specific and overall survival of diabetic castration-resistant prostate cancer patients. J Urol. 2017;197(4):1068-1075. doi:10.1016/j.juro.2016.10.069

12. Lee CK, Jung M, Jung I, et al. Cumulative metformin use and its impact on survival in gastric cancer patients after gastrectomy. Ann Surg. 2016;263(1):96-102. doi:10.1097/SLA.0000000000001086

13. Lacroix O, Couttenier A, Vaes E, et al. Impact of metformin on gastric adenocarcinoma survival: a Belgian population based study. Cancer Epidemiol. 2018;53:149-155. doi:10.1016/j.canep.2018.02.001

14. Buchler T, Klapka R, Melichar B, et al. Sunitinib followed by sorafenib or vice versa for metastatic renal cell carcinoma - data from the Czech registry. Ann Oncol. 2012;23(2):395-401. doi:10.1093/annonc/mdr065

15. Therasse P, Arbuck SG, Eisenhauer EA, et al. New guidelines to evaluate the response to treatment in solid tumours. European Organization for Research and Treatment of Cancer, National Cancer Institute of the United States, National Cancer Institute of Canada. J Natl Cancer Inst. 2000;92(3):205-216. doi:10.1093/jnci/92.3.205

16. Kahn BB, Alquier T, Carling D, et al. AMP-activated protein kinase: ancient energy gauge provides clues to modern understanding of metabolism. Cell Metab. 2005;1(1):15-25. doi:10.1016/j. cmet.2004.12.003

17. Sośnicki S, Kapral M, Węglarz L. Molecular targets of metformin antitumor action. Pharmacol Rep. 2016;68(5):918-925. doi:10.1016/ j.pharep.2016.04.021

18. Woodard J, Joshi S, Viollet B, et al. AMPK as a therapeutic target in renal cell carcinoma. Cancer Biol Ther. 2010;10(11):1168-1177. doi:10.4161/cbt.10.11.13629

19. Decensi A, Puntoni M, Goodwin P, et al. Metformin and cancer risk in diabetic patients: a systematic review and meta-analysis. Cancer Prev Res (Phila). 2010;3(11):1451-1461. doi:10.1158/1940-6207. CAPR-10-0157

20. Gandini S, Puntoni M, Heckman-Stoddard BM, et al. Metformin and cancer risk and mortality: a systematic review and meta-analysis taking into account biases and confounders. Cancer Prev Res (Phila). 2014;7(9):867-885. doi:10.1158/1940-6207.CAPR-13-0424

21. Li Y, Hu L, Xia Q, et al. The impact of metformin use on survival in kidney cancer patients with diabetes: a meta-analysis. Int Urol Nephrol. 2017;49(6):975-981. doi:10.1007/s11255-017-1548-4

22. Jiralerspong S, Palla SL, Giordano SH, et al. Metformin and pathologic complete responses to neoadjuvant chemotherapy in diabetic patients with breast cancer. J Clin Oncol. 2009;27(20):3297-3302. doi: 10.1200/JCO.2009.19.6410

23. Lin JJ, Gallagher EJ, Sigel K, et al. Survival of patients with stage IV lung cancer with diabetes treated with metformin. Am J Respir Crit Care Med. 2015;191(4):448-454. doi:10.1164/rccm.201407$13950 \mathrm{OC}$

24. Choi Y, Kim TY, Oh DY, et al. The impact of diabetes mellitus and metformin treatment on survival of patients with advanced pancreatic cancer undergoing chemotherapy. Cancer Res Treat. 2016;48 (1):171-179. doi:10.4143/crt.2014.292

25. Psutka SP, Boorjian SA, Lohse CM, et al. The association between metformin use and oncologic outcomes among surgically treated diabetic patients with localized renal cell carcinoma. Urol Oncol. 2015;33(2):67 e15-23. doi:10.1016/j.urolonc.2014.07.008

26. Ersoy C, Kiyici S, Budak F, et al. The effect of metformin treatment on VEGF and PAI-1 levels in obese type 2 diabetic patients. Diabetes Res Clin Pract. 2008;81(1):56-60. doi:10.1016/j. diabres.2008.02.006 
27. Lund SS, Tarnow L, Stehouwer CD, et al. Impact of metformin versus repaglinide on non-glycaemic cardiovascular risk markers related to inflammation and endothelial dysfunction in non-obese patients with type 2 diabetes. Eur $J$ Endocrinol. 2008;158 (5):631-641. doi:10.1530/EJE-07-0815

28. Hirsch HA, Iliopoulos D, Struhl K. Metformin inhibits the inflammatory response associated with cellular transformation and cancer stem cell growth. Proc Natl Acad Sci USA. 2013;110(3):972-977. doi:10.1073/pnas.1221055110

29. Esfahanian N, Shakiba Y, Nikbin B, et al. Effect of metformin on the proliferation, migration, and MMP-2 and -9 expression of human umbilical vein endothelial cells. Mol Med Rep. 2012;5(4):1068-1074. doi:10.3892/mmr.2012.753

30. Hakimi AA, Chen L, Kim PH, et al. The impact of metformin use on recurrence and cancer-specific survival in clinically localized high-risk renal cell carcinoma. Can Urol Assoc J. 2013;7(11-12): E687-91. doi:10.5489/cuaj.1447

31. Nayan M, Juurlink DN, Austin PC, et al. Canadian Drug Safety and Effectiveness Research Network (CDSERN). Medication use and kidney cancer survival: a population-based study. Int $J$ Cancer. 2018;142(9):1776-1785. doi:10.1002/ijc.31204
32. Cheng JJ, Li H, Tan HS, et al. Metformin use in relation with survival outcomes of patients with renal cell carcinoma. Clin Genitourin Cancer. 2016;14(2):168-175. doi:10.1016/j.clgc.2015.12.012

33. Keizman D, Ish-Shalom M, Sella A, et al. Metformin use and outcome of sunitinib treatment in patients with diabetes and metastatic renal cell carcinoma. Clin Genitourin Cancer. 2016;14(5):420-425. doi:10.1016/j.clgc.2016.04.012

34. Hamieh L, McKay RR, Lin X, et al. Effect of metformin use on survival outcomes in patients with metastatic renal cell carcinoma. Clin Genitourin Cancer. 2017;15(2):221-229. doi:10.1016/j.clgc.2016.06.017

35. Pasha M, Sivaraman SK, Frantz R, et al. Metformin induces different responses in clear cell renal cell carcinoma caki cell lines. Biomolecules. 2019;9(3):113. doi:10.3390/biom9030113

36. Chrom P, Stec R, Semeniuk-Wojtas A, et al. Fuhrman grade and neutrophil-to-lymphocyte ratio influence on survival in patients with metastatic renal cell carcinoma treated with first-line tyrosine kinase inhibitors. Clin Genitourin Cancer. 2016;14(5):457-464. doi:10.1016/j.clgc.2016.02.005

\section{Publish your work in this journal}

Cancer Management and Research is an international, peer-reviewed open access journal focusing on cancer research and the optimal use of preventative and integrated treatment interventions to achieve improved outcomes, enhanced survival and quality of life for the cancer patient.
The manuscript management system is completely online and includes a very quick and fair peer-review system, which is all easy to use. Visit http://www.dovepress.com/testimonials.php to read real quotes from published authors. 